\title{
The timing and duration of depressive symptoms from adolescence to young adulthood and young adults' NEET status: the role of educational attainment
}

\author{
Karin Veldman ${ }^{1}$ (D) Sijmen A. Reijneveld ${ }^{1}$. Johan Hviid Andersen ${ }^{2} \cdot$ Trine Nøhr Winding $^{2} \cdot$ Merete Labriola $^{3,4}$. \\ Thomas Lund ${ }^{5,6} \cdot$ Ute Bültmann ${ }^{1}$
}

Received: 8 November 2020 / Accepted: 9 July 2021 / Published online: 13 August 2021

(c) The Author(s) 2021

\begin{abstract}
Purpose Depressive symptoms are negatively associated with labour market outcomes but whether the timing and duration of depressive symptoms or educational attainment (EA) affect NEET (Neither in Employment, Education, nor Training) is unknown. Therefore, this study aims to examine the effects of timing and duration of depressive symptoms in adolescence and the moderating and mediating role of EA on NEET in young adulthood.

Methods Data were used from 1512 participants in the Vestliv Study, a Danish prospective cohort study. Depressive symptoms were measured at age 14, 18 and 21. EA at age 21 and NEET at age 23 were derived from national registers. Logistic regression analyses and a 4-way decomposition approach were applied.

Results Among boys, depressive symptoms at ages 14 and 21 increased the risk of NEET (OR 1.65, 95\% CI 1.00-2.74 and OR 2.20, 95\% CI 1.37-3.53). Among girls, this regarded depressive symptoms at ages 18 and 21 (OR 1.76, 95\% CI 1.26-2.46 and OR 1.59, 95\% CI 1.13-2.22). For the duration of depressive symptoms, among boys any depressive symptoms increased the risk of NEET. Among girls, only persistent depressive symptoms increased the risk of NEET. EA did not mediate or moderate the association between depressive symptoms and NEET.

Conclusion The timing and duration of depressive symptoms in adolescence matter for the association with NEET in young adulthood, with a double burden for those with both depressive symptoms and low EA. The results emphasize the importance of support for those who experience depressive symptoms in the school-to-work transition.
\end{abstract}

Keywords Depressive symptoms · Educational attainment $\cdot$ NEET status $\cdot$ Adolescence $\cdot$ Young adulthood $\cdot$ Life course perspective

Karin Veldman

k.veldman@umcg.nl

1 Department of Health Sciences, Community and Occupational Medicine, University Medical Center Groningen, University of Groningen, FA 10, P.O. Box 30001, 9700 RB Groningen, The Netherlands

2 Danish Ramazzini Centre, Department of Occupational Medicine, University Research Clinic, Regional Hospital West Jutland, Herning, Denmark

3 Section of Clinical Social Medicine and Rehabilitation, Department of Public Health, University of Aarhus, Aarhus C, Denmark

4 NORCE Norwegian Research Centre, Bergen, Norway

5 Center for Social Medicine, Bispebjerg and Frederiksberg Hospital, Copenhagen, Denmark

6 Department of Public Health, University of Copenhagen, Copenhagen, Denmark

\section{Introduction}

Depressive symptoms affect several labour market outcomes, including NEET status (Neither in Education, Employment nor Training) [1-14], which may be due to a negative effect of depressive symptoms on the level of energy, concentration and motivation [4]. Also, poor labour market participation may affect mental health negatively $[6,14]$. To validly study the impact of depression on NEET, depression should be measured before young adults are exposed to the work environment [15]. A recent review of Clayborne et al. showed that adolescent depressive symptoms increase the risk of unemployment, but none of the included studied measured depressive symptoms at different time points [7]. Examining depressive symptoms at one time point, leaves it unclear whether the 
effect of depressive symptoms on NEET is dependent of the timing and duration of depressive symptoms.

With regard to the timing of depressive symptoms, the onset of depression early in life is a risk factor for more frequent and longer depressive episodes later in life [16], but evidence is scarce on how this translates to NEET status. Recently, De Groot et al. showed that the association between internalizing problems and having a paid work is independent of the timing of these problems, i.e. problems at all ages during (pre)adolescence were associated with having no paid job [17]. In line with this, Narusyte et al. found that internalising problems at different ages in childhood and adolescence were associated with sickness absence and receiving disability pension in young adulthood [18].

With regard to the duration of depressive symptoms, prior research has shown that a history of mental health problems is associated with poor labour market outcomes [19]. When a longer duration was compared to a shorter duration of mental health problems, an exposure-response relationship was found, i.e. the risk of having no paid work increased with the duration of internalizing problems [17].

It is known from the literature that depressive symptoms are associated with educational attainment [20-25], but evidence lacks almost fully on the role of educational attainment in linking depressive symptoms during adolescence to NEET status in young adulthood. Educational attainment might shape this association between depressive symptoms in adolescence and NEET status in young adulthood either as a moderator or as a mediator. As potential moderator, a higher level of educational attainment buffers the negative effect of depressive symptoms in adolescence on NEET status in young adulthood. Through education, young adults learn general skills, like solving problems and developing ideas, which add to their human capital [26]. Moreover, young adults have access to or are part of social networks through college attendance, which positively affects their social capital [26]. More human and social capital will help adolescents to cope better with their depressive symptoms $[27,28]$, and thus may buffer the effect of depressive symptoms on the risk of becoming in NEET. As potential mediator, depressive symptoms negatively affects educational attainment, and educational attainment affects labour market participation negatively, i.e., depressed adolescents are less likely to be successful at school, which is a disadvantage for entering the labour market [20-25]. The level of educational attainment determines chances at the labour market, e.g. a low level of educational attainment is linked to lower income and higher unemployment rates and a high level of educational attainment to higher income and lower unemployment rates [29]. A recent study of Johar et al. showed a mediating effect of the level of educational attainment on the association between adolescent depression and adult wages [9].
Given the limited evidence on the effects of timing and duration of depressive symptoms on NEET and the role of education, including the importance to inform policy and practice about when and how to intervene in the lives of adolescents and young adults, the present study was conducted. The aims of this longitudinal study were as follows: (1) to examine the effects of timing and duration of depressive symptoms from adolescence to young adulthood on NEET in young adulthood, and (2) to investigate whether the level of educational attainment moderates or mediates this association among 1512 Danish young adults participating in the Vestliv study. All analyses were conducted for the total sample and for boys and girls separately, as depressive symptoms among girls are more prevalent than among boys [30], and associations with educational attainment are found only among girls [22, 23].

\section{Materials and methods}

\section{Ethical statement}

The study was approved by the Danish Data Protection Agency, according to Danish law (Act on Research Ethics Review of Health Research Projects). Ethical approval or informed consent is not required for questionnaire and register-based studies. The reporting of this study conforms to the STROBE statement [31].

\section{Sample design}

The West Jutland cohort study (Vestliv) is a prospective cohort study among Danish adolescents [32,33]. All adolescents born in 1989 and living in the county of Ringkjøbing, Denmark in $2004(N=3681)$ were selected for participation in the Vestliv study. Contact information was derived from the Central Office of Civil Registration and from public schools. Participants were recruited either at school, or when not at school, by mail. A total of 3054 participants (83.0\% of the initial sample, mean age 14.4 years, SD 0.49) completed the baseline questionnaire in 2004. In 2007, 2181 participants (71.4\% of baseline, mean age 17.8 years, SD 0.38$)$ and finally in 2010, 1945 completed the follow-up questionnaires (63.7\% of baseline, participants were 20 or 21 years old, the exact age was not measured). The present study used 9-year follow-up data of 1512 Vestliv participants who had complete data for all waves.

\section{Data management and linkage}

Data on depressive symptoms was derived from the questionnaires. Data on educational attainment, NEET status, parental educational level and family composition was 
derived from Danish registers. NEET status was derived from the DREAM register, a Danish database that includes all social transfer payments, i.e. payments related to unemployment benefits, sickness absence compensation, disability pension, state educational grants, immigration and death [34]. Level of educational attainment of the participants and their parents was derived from the Registers of Education, which include individual-level information about enrolment and completion of Danish students per education institution [35]. Family composition was derived from the Danish Civil Registration System, which includes information of individual characteristics such as gender, date of birth, citizenship and identity of parents [36]. Data from the questionnaires and the registers was merged using the CPR number (a personal identification number) of each participant.

\section{Measures}

Depressive symptoms were measured with the four-item version of the Center for Epidemiological Studies Depression scale for Children (CES-DC)[37] in 2004, 2007 and 2010 when participants were aged 14, 18 and 21 years, respectively. The four items were: 'I was happy', 'I felt like friends were not friendly or that they didn't want to be with me', 'I felt sad' and 'it was hard to get started doing things'. Participants could answer with 'not at all', 'a little', 'some' and 'a lot'. The first item was reversed and higher CES-DC scores indicate higher levels of depressive symptoms. Cronbach's alphas for the CES-DC were 0.63 in 2004 and 2007, and 0.70 in 2010, indicating an acceptable reliability. To measure timing, depressive symptoms were dichotomized for each time point at the 80 th percentile $(0=$ No (severe) depressive symptoms, $1=$ severe depressive symptoms) [38, 39]. To measure duration of depressive symptoms, dichotomized depressive symptoms were categorized across all time points as follows: (1) No exposure: participants who reported no depressive symptoms at any time point; (2) Single exposure: participants who reported depressive symptoms at one time point (3) Persistent exposure: participants who reported depressive symptoms at two or three time points.

NEET was defined as receiving social transfer payments in a 52-week period from week 35 in 2011 through week 35 in 2012, when participants were 23 years of age. Participants were categorized into two following groups: (1) in NEET when receiving social transfer payments, except maternity leave benefits and state educational grants and (2) not in NEET when receiving no social transfer payments, or when receiving maternity leave benefits or state educational grants (Lund et al. [40]). The social transfer payments of participants in NEET were either health-related benefits (sickness absence compensation, vocational rehabilitation benefits, and permanent disability benefits) or unemployment benefits, including leave benefits and training benefits offered to people after 4 weeks of unemployment.

Level of educational attainment concerned the educational level after compulsory school in October 2010 when participants were 21 years of age. The level of educational attainment was dichotomized as follows: (1) Completed secondary education: participants who had completed a secondary education, (2) Not completed secondary education: participants who were still attaining a secondary education, who dropped out of their last secondary education and never attained another, or who never attained a secondary education.

Parental educational level was based on years of education at the end of 2003. Parental educational level was classified as follows: (1) < 10 years, (2) 10-12 years, (3) $13-15$ years, and $(4)>15$ years.

Family composition was derived from the register at the end of 2003 and was dichotomized into the following: (0) Living with two parents or (1) living with one parent or not living with parents.

\section{Data analyses}

Descriptive data were presented for all variables for the total sample, by sex and by NEET status. To test for differences between boys and girls, and between NEETs and non-NEETs, chi-square-tests were performed.

To assess the effect of timing and duration of depressive symptoms on NEET status, binary logistic regression analyses were performed. Crude associations between depressive symptoms and NEET status were calculated (Model 1), followed by adjustments for parental educational level, family composition and educational attainment (Model 2). For the assessment of the association between depressive symptoms at age 18 or 21 and NEET status, the analyses were adjusted for earlier depressive symptoms (i.e. at age 14 and/or age 18) (Model 3). Next, a 4-way decomposition approach was used to identify direct, mediation and interaction effects [41]. The total excess relative risk was decomposed into the following four components:

(1) The effect of depressive symptoms on NEET status, while controlling for educational attainment, i.e. the Controlled Direct Effect (CDE).

(2) The combined effect of depressive symptoms and educational attainment on NEET status, that is attributable to interaction but not to mediation, i.e. the Reference Interaction $\left(\mathrm{INT}_{\text {ref }}\right)$.

(3) The combined effect of depressive symptoms and educational attainment on NEET status, that is attributable to both interaction and mediation, i.e. the Mediated Interaction $\left(\mathrm{INT}_{\mathrm{med}}\right)$. 
(4) The effect of depressive symptoms on NEET statusthat is purely mediated by educational attainment, i.e. the Pure Indirect Effect (PIE).

In this 4-way decomposition approach depressive symptoms at age 21 were not included, as educational attainment as potential mediator was measured at age $20 / 21$, i.e. before depressive symptoms as determinant were measured. All analyses were conducted for the total sample and for boys and girls separately. Analyses were conducted in Stata version 16.

Characteristics of participants who dropped out or had missing data $(N=2169,58.9 \%)$ were compared to characteristics of participants with complete data $(N=1512$, $41.1 \%$ ). Those characteristics include sex, parental educational level, family composition, level of educational attainment and NEET status.

\section{Results}

\section{Sample characteristics}

The total sample consisted of 1512 young adults (41.8\% boys). Young adults who completed secondary education were more often in school or at work than young adults who did not $(89.7 \%$ vs $80.7 \%)$. Young adults in NEET reported significantly more often severe depressive symptoms at age 14, 18 and 21, compared to young adults who were in school or at work. Table 1 shows the sample characteristics for the total sample, by sex and by NEET status at age 23 .

\section{Timing and duration of depressive symptoms at ages 14, 18 and 21 and NEET status at age 23}

For the timing of depressive symptoms, Table 2 shows that for the total sample, depressive symptoms at age 14, 18 or 21 increased the risk of being NEET at age 23 years [odds ratios (OR), 95\% confidence intervals (CI), ranging

Table 1 Background characteristics for the total sample, by sex and by NEET status at age $23(N=1512$, Vestliv study)

\begin{tabular}{|c|c|c|c|c|c|c|c|c|c|c|c|c|c|}
\hline \multirow[t]{3}{*}{ Variables } & \multirow[t]{3}{*}{$\mathrm{Age}^{\mathrm{a}}$} & \multirow{3}{*}{$\begin{array}{l}\text { Total } \\
N\end{array}$} & \multirow[t]{3}{*}{$\%$} & \multirow{3}{*}{$\begin{array}{l}\text { Boys } \\
N\end{array}$} & \multirow[t]{3}{*}{$\%$} & \multirow{3}{*}{$\begin{array}{l}\text { Girls } \\
N\end{array}$} & \multirow[t]{3}{*}{$\%$} & \multirow[t]{3}{*}{$p$ value } & \multirow{2}{*}{\multicolumn{2}{|c|}{$\begin{array}{l}\text { NEET } \\
\text { status }\end{array}$}} & \multirow{2}{*}{\multicolumn{2}{|c|}{ Not NEET }} & \multirow[t]{3}{*}{$p$ value } \\
\hline & & & & & & & & & & & & & \\
\hline & & & & & & & & & $\mathrm{N}$ & $\%$ & $\mathrm{~N}$ & $\%$ & \\
\hline Parental educational level & 14 & & & & & & & 0.38 & & & & & 0.68 \\
\hline Low & & 126 & 8.3 & 48 & 7.6 & 78 & 8.9 & & 25 & 7.8 & 101 & 8.5 & \\
\hline Medium/High & & 1386 & 91.7 & 584 & 92.4 & 802 & 91.1 & & 297 & 92.2 & 1089 & 91.5 & \\
\hline Family composition & 14 & & & & & & & 0.36 & & & & & 0.11 \\
\hline 1 parent or no parent & & 114 & 7.5 & 43 & 6.8 & 71 & 8.1 & & 31 & 9.6 & 83 & 7.0 & \\
\hline 2 parents & & 1395 & 92.5 & 589 & 93.2 & 809 & 91.9 & & 291 & 90.4 & 1107 & 93.0 & \\
\hline Educational attainment $(N, \%)$ & $20 / 21$ & & & & & & & 0.002 & & & & & $<0.001$ \\
\hline Not completed secondary education & & 185 & 12.2 & 97 & 15.3 & 88 & 10.0 & & 62 & 19.3 & 123 & 10.3 & \\
\hline Completed secondary education & & 1327 & 87.8 & 535 & 84.7 & 792 & 90.0 & & 260 & 80.7 & 1067 & 89.7 & \\
\hline Depressive symptoms & 14 & & & & & & & 0.001 & & & & & 0.01 \\
\hline No (severe) & & 1211 & 79.4 & 529 & 83.7 & 672 & 76.4 & & 240 & 74.5 & 961 & 80.8 & \\
\hline Severe & & 311 & 20.6 & 103 & 16.3 & 208 & 23.6 & & 82 & 25.5 & 229 & 19.2 & \\
\hline Depressive symptoms & 18 & & & & & & & $<0.001$ & & & & & 0.001 \\
\hline No (severe) & & 1190 & 78.7 & 541 & 85.6 & 649 & 73.8 & & 230 & 71.4 & 960 & 80.7 & \\
\hline Severe & & 322 & 21.3 & 91 & 14.4 & 231 & 26.0 & & 92 & 28.6 & 230 & 19.3 & \\
\hline Depressive symptoms & 21 & & & & & & & $<0.001$ & & & & & $<0.001$ \\
\hline No (severe) & & 1166 & 77.1 & 519 & 82.1 & 647 & 73.5 & & 219 & 68.0 & 947 & 79.6 & \\
\hline Severe & & 346 & 22.9 & 113 & 17.9 & 233 & 26.5 & & 103 & 32.0 & 243 & 20.4 & \\
\hline Duration of depressive symptoms & $14 / 18 / 21$ & & & & & & & $<0.001$ & & & & & $<0.001$ \\
\hline No exposure & & 846 & 56.0 & 413 & 65.3 & 433 & 49.2 & & 144 & 44.7 & 702 & 59.0 & \\
\hline Single exposure & & 410 & 27.1 & 147 & 23.2 & 263 & 29.9 & & 98 & 30.4 & 312 & 26.2 & \\
\hline Persistent exposure & & 256 & 16.9 & 72 & 11.5 & 184 & 20.9 & & 80 & 24.8 & 176 & 14.8 & \\
\hline
\end{tabular}

${ }^{\mathrm{a}} \mathrm{Age}$ at which the variable was measured 
Table 2 Depressive symptoms at age 14, 18 or 21 and NEET status at age 23 for the total sample $(N=1512$, Vestliv study)

\begin{tabular}{|c|c|c|c|c|c|c|c|c|c|}
\hline & \multicolumn{2}{|c|}{ Model 1} & \multirow[t]{2}{*}{$p$ value } & \multicolumn{2}{|c|}{ Model 2} & \multirow[t]{2}{*}{$p$ value } & \multicolumn{2}{|c|}{ Model 3} & \multirow[t]{2}{*}{$p$ value ${ }^{*}$} \\
\hline & OR & $95 \% \mathrm{CI}$ & & OR & $95 \% \mathrm{CI}$ & & OR & $95 \% \mathrm{CI}$ & \\
\hline \multicolumn{10}{|l|}{ Depressive symptoms (no-severe vs severe) } \\
\hline Age 14 & 1.43 & $1.07-1.91$ & 0.02 & 1.32 & $0.98-1.77$ & 0.07 & & & \\
\hline Parental educational level (high vs low) & & & & 1.32 & $0.82-2.12$ & 0.25 & & & \\
\hline Family composition ( 2 parents vs else) & & & & 1.34 & $0.85-2.09$ & 0.21 & & & \\
\hline $\begin{array}{l}\text { Educational attainment (completed vs not completed sec- } \\
\text { ondary education) }\end{array}$ & & & & 2.16 & 1.53-3.04 & $<0.001$ & & & \\
\hline Gender (girls vs boys) & & & & 1.53 & 1.18-1.99 & 0.002 & & & \\
\hline \multicolumn{10}{|l|}{ Depressive symptoms (no-severe vs severe) } \\
\hline Age 18 & 1.67 & $1.26-2.21$ & $<0.001$ & 1.55 & $1.16-2.07$ & 0.003 & 1.50 & $1.12-2.01$ & 0.007 \\
\hline Age 14 & & & & & & & 1.24 & $0.92-1.67$ & 0.17 \\
\hline Parental educational level (high vs low) & & & & 1.35 & $0.84-2.17$ & 0.22 & 1.36 & $0.84-2.19$ & 0.21 \\
\hline Family composition ( 2 parents vs else) & & & & 1.38 & $0.88-2.16$ & 0.16 & 1.36 & $0.86-2.12$ & 0.19 \\
\hline $\begin{array}{l}\text { Educational attainment (completed vs not completed sec- } \\
\text { ondary education) }\end{array}$ & & & & 2.15 & $1.53-3.03$ & $<0.001$ & 2.13 & $1.51-3.00$ & $<0.001$ \\
\hline Gender (girls vs boys) & & & & 1.48 & 1.13-1.92 & 0.004 & 1.46 & $1.12-1.90$ & 0.005 \\
\hline \multicolumn{10}{|l|}{ Depressive symptoms (no-severe vs severe) } \\
\hline Age 21 & 1.83 & $1.39-2.41$ & $<0.001$ & 1.65 & $1.24-2.18$ & 0.001 & 1.50 & $1.12-2.00$ & 0.007 \\
\hline Age 18 & & & & & & & 1.38 & $1.03-1.86$ & $\mathbf{0 . 0 3}$ \\
\hline Age 14 & & & & & & & 1.16 & $0.85-1.57$ & 0.35 \\
\hline Parental educational level (high vs low) & & & & 1.38 & $0.86-2.22$ & 0.19 & 1.41 & $0.87-2.27$ & 0.16 \\
\hline Family composition ( 2 parents vs else) & & & & 1.36 & $0.87-2.12$ & 0.18 & 1.35 & $0.86-2.12$ & 0.19 \\
\hline $\begin{array}{l}\text { Educational attainment (completed vs not completed sec- } \\
\text { ondary education) }\end{array}$ & & & & 2.02 & $1.43-2.86$ & $<0.001$ & 2.00 & $1.42-2.83$ & $<0.001$ \\
\hline Gender (girls vs boys) & & & & 1.49 & 1.14-1.94 & 0.003 & 1.42 & $1.09-1.86$ & 0.009 \\
\hline
\end{tabular}

Bold numbers refer to findings with a p-value $<0.05$

Model 1: Crude, univariate, Model 2: Adjusted for parental educational level, family composition and educational attainment, Model 3: Model $2+$ depressive symptoms at age 14 and/or age 18

OR odds ratio, $95 \%$ CI 95\% confidence interval

from $1.43,1.07-1.91$ to $1.83,1.39-2.41]$. Among boys, severe depressive symptoms at age 14 or 21 increased the risk of being NEET [OR, 95\% CI 1.65, 1.00-2.74; and 2.20, 1.37-3.53) (Table 3). Adjustment of parental educational level, family composition and educational attainment attenuated the association between depressive symptoms at age 14 and being NEET. Among girls, severe depressive symptoms at age 18 and 21 increased the risk of being NEET (OR 1.76, 1.26-2.46; 1.59, 1.13-2.22) (Table 4). Adjustment for earlier depressive symptoms revealed that only the effect of depressive symptoms at age 18 remained significant (OR 1.60, 1.13-2.27).

For the duration of depressive symptoms, any both a single or persistent exposure of severe depressive symptoms increased the risk of being NEET for the total sample and among boys (ORs ranging from 1.53 to 2.22) (Table 5). Among girls, only persistent exposure increased the risk of being NEET (OR 2.08, 1.41-3.06) (Table 5).

\section{Mediation and moderation effects of educational attainment on the association between depressive symptoms and NEET status}

For the total sample and for boys and girls separately, on top of the effects of depressive symptoms, not completing secondary education increased the risk of being NEET (ORs ranging from 1.93 to 2.21, Tables 2,3, 4). This result indicated that for the models in which depressive symptoms increased the risk of being NEET, the effect of depressive symptoms and educational attainment on NEET status was multiplicative, as a logistic model is by nature.

For the total sample and for boys, the results showed that depressive symptoms were not associated with educational 
Table 3 Depressive symptoms at age 14,18 or 21 and NEET status at age 23 for boys ( $N=632$, Vestliv study)

\begin{tabular}{|c|c|c|c|c|c|c|c|c|c|}
\hline & \multicolumn{2}{|c|}{ Model 1} & \multirow[t]{2}{*}{$p$ value } & \multicolumn{2}{|c|}{ Model 2} & \multirow[t]{2}{*}{$p$ value } & \multicolumn{2}{|c|}{ Model 3} & \multirow[t]{2}{*}{$p$ value } \\
\hline & OR & $95 \% \mathrm{CI}$ & & OR & $95 \% \mathrm{CI}$ & & OR & $95 \% \mathrm{CI}$ & \\
\hline \multicolumn{10}{|l|}{ Depressive symptoms (no-severe vs severe) } \\
\hline Age 14 & 1.65 & $1.00-2.74$ & 0.05 & 1.63 & $0.98-2.73$ & 0.06 & & & \\
\hline Parental educational level (high vs low) & & & & 1.40 & $0.61-3.19$ & 0.43 & & & \\
\hline Family composition (2 parents vs else) & & & & 1.54 & $0.73-3.26$ & 0.26 & & & \\
\hline $\begin{array}{l}\text { Educational attainment (completed vs not completed second- } \\
\text { ary education) }\end{array}$ & & & & 2.20 & $1.33-3.65$ & 0.002 & & & \\
\hline \multicolumn{10}{|l|}{ Depressive symptoms (no-severe vs severe) } \\
\hline Age 18 & 1.19 & $0.68-2.08$ & 0.55 & 1.23 & $0.70-2.17$ & 0.48 & 1.12 & $0.62-2.00$ & 0.71 \\
\hline Age 14 & & & & & & & 1.60 & $0.95-2.71$ & 0.08 \\
\hline Parental educational level (high vs low) & & & & 1.32 & $0.58-3.01$ & 0.50 & 1.39 & $0.61-3.17$ & 0.44 \\
\hline Family composition ( 2 parents vs else) & & & & 1.64 & $0.78-3.44$ & 0.19 & 1.55 & $0.74-3.28$ & 0.25 \\
\hline $\begin{array}{l}\text { Educational attainment (completed vs not completed second- } \\
\text { ary education) }\end{array}$ & & & & 2.21 & $1.34-3.66$ & 0.002 & 2.21 & 1.33-3.66 & 0.002 \\
\hline \multicolumn{10}{|l|}{ Depressive symptoms (no-severe vs severe) } \\
\hline Age 21 & 2.20 & $1.37-3.53$ & 0.001 & 2.08 & $1.28-3.37$ & 0.003 & 1.99 & 1.19-3.32 & 0.008 \\
\hline Age 18 & & & & & & & 0.91 & $0.84-2.47$ & 0.18 \\
\hline Age 14 & & & & & & & 1.44 & $0.49-1.67$ & 0.76 \\
\hline Parental educational level (high vs low) & & & & 1.46 & $0.63-3.37$ & 0.38 & 1.50 & $0.65-3.48$ & 0.34 \\
\hline Family composition (2 parents vs else) & & & & 1.58 & $0.75-3.34$ & 0.23 & 1.52 & $0.71-3.22$ & 0.28 \\
\hline $\begin{array}{l}\text { Educational attainment (completed vs not completed second- } \\
\text { ary education) }\end{array}$ & & & & 2.07 & $1.24-3.44$ & 0.005 & 2.08 & $1.25-3.47$ & 0.005 \\
\hline
\end{tabular}

Bold numbers refer to findings with a p-value $<0.05$

Model 1: Crude, univariate, Model 2: Adjusted for parental educational level, family composition and educational attainment, Model 3: Model $2+$ depressive symptoms at age 14 and/or age 18

OR odds ratio, $95 \%$ CI 95\% confidence interval

attainment (data not shown). Therefore, the 4-way decomposition approach was only performed for girls. Among girls, the 4-way decomposition approach did not reveal any moderating or mediating or interaction effects of the association between depressive symptoms and NEET status (Online resource Table S1).

Repeating the analyses with a CES-DC cut-off at the $90 \%$ percentile yielded similar but stronger associations. The comparative analyses showed that, compared to participants with complete data, those who dropped-out or had missing data, were more often boys ( $58.6 \%$ vs. $41.8 \%)$, more often had low educated parents $(17.8 \%$ vs. $8.3 \%)$, more often came from single parent families $(20.1 \%$ vs. $7.5 \%)$, more often had low levels of educational attainment $(30.4 \%$ vs. $12.2 \%)$, and were more often NEET (26.8\% vs. $21.3 \%$ ) (Online resource Table S2).

\section{Discussion}

In the present study, we found that the timing of severe depressive symptoms during adolescence matters for the risk of being NEET in young adulthood. Among boys, severe depressive symptoms at age 14 or 21 increased the risk of being NEET, whereas among girls, only severe depressive symptoms at age 18 were increased the risk of being NEET. Regarding the duration of severe depressive symptoms, we found that among boys any severe depressive symptoms increased the risk of being NEET. For girls, only persistent depressive symptoms increased the risk of being NEET. We found that both severe depressive symptoms, at ages 18 for girls and 14 and 21 for boys, and educational attainment increased the risk of being NEET. Educational attainment at age 20/21 did not moderate or mediate the association between depressive symptoms and NEET status.

For boys, severe depressive symptoms were dependent of the timing of these problems, but independent of the duration, with severe depressive symptoms at ages 14 and 21 and any duration increasing the risk of being NEET. This 
Table 4 Depressive symptoms at age 14, 18 or 21 and NEET status at age 23 for girls $(N=880$, Vestliv study)

\begin{tabular}{|c|c|c|c|c|c|c|c|c|c|}
\hline & \multicolumn{2}{|c|}{ Model 1} & \multirow[t]{2}{*}{$p$ value } & \multicolumn{2}{|c|}{ Model 2} & \multirow[t]{2}{*}{$p$ value } & \multicolumn{2}{|c|}{ Model 3} & \multirow[t]{2}{*}{$p$ value } \\
\hline & OR & $95 \% \mathrm{CI}$ & & OR & $95 \% \mathrm{CI}$ & & OR & $95 \% \mathrm{CI}$ & \\
\hline \multicolumn{10}{|l|}{ Depressive symptoms (no-severe vs severe) } \\
\hline Age 14 & 1.27 & $0.89-1.81$ & 0.19 & 1.20 & $0.84-1.71$ & 0.33 & & & \\
\hline Parental educational level (high vs low) & & & & 1.30 & $0.73-2.31$ & 0.38 & & & \\
\hline Family composition (2 parents vs else) & & & & 1.23 & $0.70-2.15$ & 0.47 & & & \\
\hline $\begin{array}{l}\text { Educational attainment (completed vs not completed second- } \\
\text { ary education) }\end{array}$ & & & & 2.15 & $1.35-3.43$ & 0.001 & & & \\
\hline \multicolumn{10}{|l|}{ Depressive symptoms (no-severe vs severe) } \\
\hline Age 18 & 1.76 & $1.26-2.46$ & 0.001 & 1.70 & 1.21-2.39 & 0.002 & 1.67 & $1.19-2.37$ & 0.003 \\
\hline Age 14 & & & & & & & 1.11 & $0.77-1.59$ & 0.59 \\
\hline Parental educational level (high vs low) & & & & 1.38 & $0.77-2.48$ & 0.28 & 1.38 & $0.77-2.48$ & 0.28 \\
\hline Family composition ( 2 parents vs else) & & & & 1.25 & $0.72-2.20$ & 0.43 & 1.25 & $0.71-2.18$ & 0.44 \\
\hline $\begin{array}{l}\text { Educational attainment (completed vs not completed second- } \\
\text { ary education) }\end{array}$ & & & & 2.06 & $1.29-3.29$ & 0.003 & 2.04 & $1.27-3.26$ & 0.003 \\
\hline \multicolumn{10}{|l|}{ Depressive symptoms (no-severe vs severe) } \\
\hline Age 21 & 1.59 & $1.13-2.22$ & 0.007 & 1.47 & $1.04-2.07$ & $\mathbf{0 . 0 3}$ & 1.33 & $0.93-1.90$ & 0.12 \\
\hline Age 18 & & & & & & & 1.60 & $1.13-2.27$ & 0.008 \\
\hline Age 14 & & & & & & & 1.06 & $0.73-1.53$ & 0.77 \\
\hline Parental educational level (high vs low) & & & & 1.35 & $0.75-2.41$ & 0.32 & 1.42 & $0.79-2.54$ & 0.25 \\
\hline Family composition (2 parents vs else) & & & & 1.24 & $0.71-2.17$ & 0.44 & 1.25 & $0.71-2.19$ & 0.44 \\
\hline $\begin{array}{l}\text { Educational attainment (completed vs not completed second- } \\
\text { ary education) }\end{array}$ & & & & 2.01 & $1.25-3.22$ & 0.004 & 1.93 & $1.20-3.10$ & 0.007 \\
\hline
\end{tabular}

Bold numbers refer to findings with a p-value $<0.05$

Model 1: Crude, univariate, Model 2: Adjusted for parental educational level, family composition and educational attainment, Model 3: Model $2+$ depressive symptoms at age 14 and/or age 18

OR odds ratio, $95 \%$ CI 95\% confidence interval

may be explained by the fact that boys and men tend to seek less help when feeling depressed than girls and women [42]. Compared to women, men may perceive more stigmas and more often believe that they have to deal with their feelings alone [43, 44]. Regarding the association of severe depressive symptoms at age 14 with NEET, a cautious interpretation is warranted as the results were borderline significant.

Among girls, only depressive symptoms at age 18 and a persistent exposure to severe depressive symptoms increased the risk of being NEET. An explanation may be that girls are especially susceptible for depressive symptoms during this phase in life, i.e. emerging adulthood. This is supported by the finding of an increased odds ratio for the association of depressive symptoms at age 21 and NEET status, although this association was no longer significant in the full adjusted model. Previous studies reported similar findings, i.e. that depressive symptoms in late adolescence and/or young adulthood are associated with work outcomes [2, 7-13], but only a few have examined the timing of depressive symptoms [17, 18]. In contrast to our findings, De Groot et al. [17] and Narusyte et al. [18] reported the effect of internalizing problems on having paid work, sickness absence and disability pension to be independent of the timing of these problems $[17,18]$, whereas we found that the effect of depressive symptoms on the risk of being NEET depended on timing but with different time points for boys and girls. This difference may be explained by the fact that De Groot et al. and Narusyte et al. did not stratify by sex, whereas we did. This explanation is supported by the fact that we also did not find an effect of the timing of depressive symptoms if we performed the analyses for our total sample, i.e. without stratification. More sex-stratified research taking depressive symptoms at different life phases into account is needed to improve our understanding of the effect of the timing of depressive symptoms with respect to later life work outcomes.

Depressive symptoms and educational attainment were found to have a multiplicative effect on NEET status, indicating that adolescents with severe depressive symptoms and poor educational attainment have a double burden. No moderating effects of the level of educational attainment were found, suggesting that the level educational attainment does not buffer adverse effects of depressive symptoms during adolescence on NEET status in young adulthood. It cannot 
Table 5 Duration of depressive symptoms from age 14-21 and NEET status at age 23 for the total sample and by sex ( $N=1512$, Vestliv study)

\begin{tabular}{|c|c|c|c|c|c|c|}
\hline & \multicolumn{2}{|c|}{ Model 1} & \multirow[t]{2}{*}{$p$ value } & \multicolumn{2}{|c|}{ Model 2} & \multirow[t]{2}{*}{$p$ value } \\
\hline & OR & $95 \% \mathrm{CI}$ & & OR & $95 \% \mathrm{CI}$ & \\
\hline \multicolumn{7}{|l|}{ Total } \\
\hline \multicolumn{7}{|l|}{ Depressive symptoms } \\
\hline No exposure (ref) & 1 & & & 1 & & \\
\hline Single exposure & $\mathbf{1 . 5 3}$ & $1.15-2.04$ & 0.004 & 1.49 & 1.11-1.99 & 0.008 \\
\hline Persistent exposure & 2.22 & 1.61-3.05 & $<0.001$ & 2.13 & $1.54-2.94$ & $<0.001$ \\
\hline Parental educational level (high vs low) & & & & 1.37 & $0.85-2.20$ & 0.20 \\
\hline Family composition (2 parents vs else) & & & & 1.35 & $0.86-2.12$ & 0.19 \\
\hline Educational attainment (completed vs not completed secondary education) & & & & 1.37 & 1.15-1.63 & $<0.001$ \\
\hline \multicolumn{7}{|l|}{ Boys $(n=632)$} \\
\hline \multicolumn{7}{|l|}{ Depressive symptoms } \\
\hline No exposure (ref) & 1 & & & 1 & & \\
\hline Single exposure & 1.81 & 1.13-2.89 & 0.01 & 1.80 & $1.11-2.90$ & 0.02 \\
\hline Persistent exposure & 2.00 & 1.10-3.65 & 0.02 & 1.93 & $1.05-3.55$ & $\mathbf{0 . 0 3}$ \\
\hline Parental educational level (high vs low) & & & & 1.41 & $0.62-3.24$ & 0.41 \\
\hline Family composition ( 2 parents vs else) & & & & 1.53 & $0.72-3.22$ & 0.27 \\
\hline Educational attainment (completed vs not completed secondary education) & & & & 1.40 & $1.08-1.82$ & 0.01 \\
\hline \multicolumn{7}{|l|}{ Girls $(n=880)$} \\
\hline \multicolumn{7}{|l|}{ Depressive symptoms } \\
\hline No exposure (ref) & 1 & & & 1 & & \\
\hline Single exposure & 1.32 & $0.91-1.90$ & 0.14 & 1.24 & $0.85-1.80$ & 0.27 \\
\hline Persistent exposure & 2.08 & $1.41-3.06$ & $<0.001$ & 1.94 & $1.30-2.88$ & 0.001 \\
\hline Parental educational level (high vs low) & & & & 1.38 & $0.77-2.48$ & 0.28 \\
\hline Family composition ( 2 parents vs else) & & & & 1.24 & $0.71-2.16$ & 0.46 \\
\hline Educational attainment (completed vs not completed secondary education) & & & & 1.42 & 1.12-1.81 & 0.004 \\
\hline
\end{tabular}

Bold numbers refer to findings with a p-value $<0.05$

Model 1: crude, Model 2: adjusted for parental educational level, family composition and educational attainment

OR odds ratio, $95 \%$ CI $95 \%$ confidence interval

be excluded that also other factors may be involved here, i.e. moderating effects might exist among adolescents coming from families with low socioeconomic position (SEP). For example, it was shown by Shafer et al. that children from families with low SEP have the highest health benefits when completing college [27]. Unfortunately, we were not able to conduct stratified analysis by family SEP because of the small number in each socioeconomic stratum.

We found no mediating effect of educational attainment on the association between depressive symptoms during adolescence and NEET status in young adulthood. Previous research of Johar et al. found for boys and girls that level of educational attainment mediated the association between depressive symptoms and employment wages, with larger mediation effects among girls than among boys [9]. Our contrasting findings might be due to the different outcome that we used, i.e. NEET status versus employment wages, or by the age of the study samples, i.e. Johar et al. measured employment wages at age 26-31 years, whereas we assessed NEET status at age 23. It may be that the mediating effect (and possibly also the moderating effect) of the level of educational attainment becomes more prominent later in adult life.

The present study has several strengths and limitations. We used data from a large population sample with 9 years of follow-up. With relatively high retention rates (almost $64 \%$ after 9-year follow up) and the use of register data (100\% data on the level of educational attainment and on NEET status), the study had a very low loss to follow-up. Our sample size was $N=1512$ after exclusion of participants who dropped out or had missing data. Comparison of participants with complete data with those who dropped out or had missing data suggests that selection may have occurred because of this, e.g. excluded participants reported lower (parental) educational levels, and were more often NEET. However, a previous comparison of those who participated and those who dropped out showed that differences in characteristics did not affect the relative risk estimates measured in the study [33], and selection bias of the risk estimates is unlikely. Next, the CES-DC was used to assess depressive 
symptoms at age 14, 18 and 21, and made full comparison of the level of depressive symptoms at the different ages possible. Officially, the CES-DC is used in the age range of 6-17 years. Differences between the child and adult version are minimal, and we chose to use the same measure over time to guarantee a full comparison. The Vestliv study has a multilevel sampling design, as participants were recruited at schools, and class level may have had an impact on the level of depressive symptoms. Data regarding school or class level were not available; therefore, we could not adjust in the analyses for potential effects of the multilevel design. However, depressive symptoms were measured when participants had already left the school, so at ages for which persistent class or school level effects on depressive symptoms are rather unlikely. NEET status was assessed only 2 years after educational attainment (at ages 23 and 21 years, respectively). Therefore, the effect of the level of educational attainment on NEET status may not have been completely visible yet and the results of this study could, therefore, be an underestimation of the real effect. The measure of NEET status used in this study is a rather crude measure, as it was defined as not receiving social transfer payments in a 52 -week period. It may be that some young adults receive social benefits for a shorter period, for example, when young adults are between jobs or between education and employment, i.e. the associations may be underestimated.

The results of this study suggest that detection and early treatment of depressive symptoms during adolescence are important to improve young adults' labour market outcomes. In Denmark, children or adolescents are not routinely screened on depressive symptoms [39], which makes it difficult to detect also less severe depressive symptoms. Early detection can initiate and target treatment to prevent depressive symptoms in adolescents and, on the long-term, may save health care costs. Given the long-term consequences and the enormous costs of depressive symptoms, there is a lot to gain on the individual and societal level. Smith and Smith have shown that the costs of childhood mental health problems in the US are immense: they reduce family incomes with 10,400 USD per year [45]. As this study with a life course perspective is one of the first on this topic, our findings have to be confirmed in further research, including a rigorous elaboration of the underlying mechanisms between depressive symptoms in adolescence and labour market participation in young adulthood to enhance the likelihood of a smooth transition into the labour market [46].

\section{Conclusion}

In conclusion, we found that both the timing and duration of severe depressive symptoms during adolescence the risk for being NEET in young adulthood. Also, we found that depressive symptoms and educational attainment have a multiplicative effect on NEET status, but educational attainment did not moderate or mediate the effect of depressive symptoms on NEET status. Our findings show that much can be gained in participation in education or the labour market by tackling this major mental health problem issue. The results of this study show that (persistent) depressive symptoms in adolescence increase the risk of being NEET in young adulthood, suggesting the importance of treatment of depressive symptoms in adolescence.

Supplementary Information The online version contains supplementary material available at https://doi.org/10.1007/s00127-021-02142-5.

Author contributions Conceptualization, KV, SAR, JHA, TNW, ML, TL and UB; Methodology, KV, TNW Software, KV, TNW; Validation, SAR, UB; Formal Analysis, KV, TNW; Investigation, JHA, ML, TL; Resources, JHA, TNW, ML, TL; Data Curation, JHA, TNW, ML, TL; Writing-Original Draft Preparation, KV; Writing-Review and Editing, SAR; JHA; TNW; ML; TL and UB; Visualization, KV; Supervision, SAR, UB; Project Administration, KV; UB Funding Acquisition, UB.

Funding K.V. was funded as part of a Netherlands Organization for Scientific Research (NWO) Vici project ('Today's youth is tomorrow's workforce: Generation Y at work'; NWO Vici 453-16-007/2735) that was granted to U.B.

Availability of data and material Upon request.

Code availability STATA version 16.1 .

\section{Declarations}

Conflict of interest The authors declare no conflict of interest.

Ethical approval Use of the data was carried out under the same conditions and with the same purpose as when originally collected and was based on approval from the Danish Data Protection Agency and their rules of data protection. According to Danish law, approval by the Ethics Committee and written informed consent are not required when data collection is carried out. Additional information is available at The National Committee on Health Research Ethics' webpage in the 'Act on Research Ethics Review of Health Research Projects' $\$ 14.2$ (available from http://www.nvk.dk/english/act-on-research).

Consent to participate See Ethics approval.

Consent for publication See Ethics approval.

Open Access This article is licensed under a Creative Commons Attribution 4.0 International License, which permits use, sharing, adaptation, distribution and reproduction in any medium or format, as long as you give appropriate credit to the original author(s) and the source, provide a link to the Creative Commons licence, and indicate if changes 
were made. The images or other third party material in this article are included in the article's Creative Commons licence, unless indicated otherwise in a credit line to the material. If material is not included in the article's Creative Commons licence and your intended use is not permitted by statutory regulation or exceeds the permitted use, you will need to obtain permission directly from the copyright holder. To view a copy of this licence, visit http://creativecommons.org/licenses/by/4.0/.

\section{References}

1. Ettner SL, Frank RG, Kessler RC (1997) The impact of psychiatric disorders on labor market outcomes. Ind Labor Relat Rev 51:64-81

2. Wickrama K, Conger RD, Lorenz FO, Jung T (2008) Family antecedents and consequences of trajectories of depressive symptoms from adolescence to young adulthood: a life course investigation. J Health Soc Behav 49:468-483

3. Egan M, Daly M, Delaney L (2016) Adolescent psychological distress, unemployment, and the Great Recession: evidence from the National Longitudinal Study of Youth 1997. Soc Sci Med 156:98-105

4. Chatterjia P, Alegría M, Takeuchi DT (2011) Psychiatric disorders and labor market outcomes: evidence from the National Comorbidity Survey-Replication. J Health Econ 30:858-868

5. Whooley M, Kiefe C, Chesney M, Markovitz J, Matthews K, Hulley S (2002) Depressive symptoms, unemployment, and loss of income: the CARDIA study. Arch Intern Med 162:2614-2620

6. Olesen SC, Butterworth P, Leach LS, Kelaher M, Pirkis J (2013) Mental health affects future employment as job loss affects mental health: findings from a longitudinal population study. BMC Psychiatry 13:144

7. Clayborne ZM, Varin M, Colman I (2019) Systematic review and meta-analysis: adolescent depression and long-term psychosocial outcomes. J Am Acad Child Adolesc Psychiatry 58:72-79

8. Fletcher J (2013) Adolescent depression and adult labor market outcomes. South Econ J 80:26-49

9. Johar M, Truong J (2014) Direct and indirect effect of depression in adolescence on adult wages. Appl Econ 46:4431-4444

10. Mousteri V, Daly M, Delaney L, Tynelius P, Rasmussen F (2019) Adolescent mental health and unemployment over the lifespan: population evidence from Sweden. Soc Sci Med 222:305-314

11. Philipson A, Alaie I, Ssegonja R, Imberg H, Copeland W, Möller M, Hagberg L, Jonsson U (2020) Adolescent depression and subsequent earnings across early to middle adulthood: a 25-year longitudinal cohort study. Epidemiol Psychiatr Sci 29(e123):1-10

12. Witt K, Milner A, Evans-Whipp T, Toumbourou JW, Patton G, LaMontagne AD (2021) Educational and employment outcomes among young australians with a history of depressive symptoms: a prospective cohort study. Int J Environ Res Public Health 18:3376

13. López-López JA, Kwong A, Washbrook E, Pearson RM, Tilling K, Fazel MS, Kidger J, Hammerton G (2019) Trajectories of depressive symptoms and adult educational and employment outcomes. BJPsych Open 6:e6

14. Adler DA, Mclaughlin TJ, Rogers WH, Chang H, Lapitsky L, Lerner D (2006) Job performance deficits due to depression. Am J Psychiatry 163:1569-1576

15. Kasl SV, Jones BA (2010) An epidemiological perspective on research design, measurement, and surveillance strategies. In: Quick J, Tetrick L (eds) Handbook of occupational health psychology, 2nd edn. American Psychological Association, Washington DC, pp 379-398

16. Birmaher B, Ryan ND, Williamson DE, Brent DA, Kaufman J, Dahl RE, Perel J, Nelson B (1996) Childhood and adolescent depression: a review of the past 10 years. Part I. J Am Acad Child Adolesc Psychiatry 35:1427-1439

17. de Groot S, Veldman K, Amick iii BC, Oldehinkel AJ, Arends I, Bültmann U, (2021) Does the timing and duration of mental health problems during childhood and adolescence matter for labour market participation of young adults? J Epidemiol Community Health. https://doi.org/10.1136/jech-2020-215994

18. Narusyte J, Ropponen A, Alexanderson K, Svedberg P (2017) Internalizing and externalizing problems in childhood and adolescence as predictors of work incapacity in young adulthood. Soc Psychiatry Psychiatr Epidemiol 52:1159-1168

19. Ormel J, Oerlemans AM, Raven D, Laceulle OM, Hartman CA, Veenstra R, Verhulst FC, Vollebergh W, Rosmalen JGM, Reijneveld SA et al (2017) Functional outcomes of child and adolescent mental disorders. Current disorder most important but psychiatric history matters as well. Psychol Med 47:1271-1282

20. Fletcher JM (2010) Adolescent depression and educational attainment: results using sibling fixed effects. Health Econ 19:855-871

21. Needham BL (2009) Adolescent depressive symptomatology and young adult educational attainment: an examination of gender differences. J Adolesc Heal 45:179-186

22. Fletcher JM (2008) Adolescent depression: diagnosis, treatment, and educational attainment. Health Econ 17:1215-1235

23. McLeod JD, Fettes DL (2007) Trajectories of failure: the educational careers of children with mental health problems. Am J Sociol 113:653-701

24. Veldman K, Bültmann U, Stewart RE, Ormel J, Verhulst FC, Reijneveld SA (2014) Mental health problems and educational attainment in adolescence: 9-year follow-up of the TRAILS study. PLoS ONE 9:e101751

25. Lee S, Tsang A, Breslau J, Aguilar-Gaxiola S, Angermeyer M, Borges G, Bromet E, Bruffaerts R, de Girolamo G, Fayyad J et al (2009) Mental disorders and termination of education in highincome and low- and middle-income countries: Epidemiological study. Br J Psychiatry 194:411-417

26. Kingston PW, Hubbard R, Lapp B, Schroeder P, Wilson J (2003) Why education matters. Am Sociol Assoc 76:53-70

27. Schafer MH, Wilkinson LR, Ferraro KF (2013) Childhood (mis) fortune, educational attainment, and adult health: contingent benefits of a college degree? Soc Forces 91:1007-1034

28. Cohen-Cline H, Beresford SA, Barrington W, Matsueda R, Wakefield J, Duncan GE (2018) Associations between social capital and depression: a study of adult twins. Heal Place 176:139-148

29. Buddin R (2012) Implications of Educational Attainment Trends for Labor Market Outcomes (ACT Research Report Series 20127, Iowa City IA.

30. Ormel J, Raven D, van Oort F, Hartman CA, Reijneveld SA, Veenstra R, Vollebergh WAM, Buitelaar J, Verhulst FC, Oldehinkel AJ (2015) Mental health in Dutch adolescents: a TRAILS report on prevalence, severity, age of onset, continuity and co-morbidity of DSM disorders. Psychol Med 45:345-360

31. STROBE Statement (2021) Strengthening the reporting of observational studies in epidemiology. http://www.strobe-statement. org/. Accessed 15 Mar 2021

32. Andersen JH, Labriola M, Lund T, Hansen CD (2013) Development of health and depressive symptoms among Danish adolescents. Socioeconomic differences and effects of life-style. Open J Prev Med 03:104-110

33. Winding TN, Andersen JH, Labriola M, Nohr E (2014) a Initial non-participation and loss to follow-up in a Danish youth cohort: implications for relative risk estimates. J Epidemiol Community Health 68:137-144

34. Hjollund NH, Larsen FB, Andersen JH (2007) Register-based follow-up of social benefits and other transfer payments: accuracy and degree of completeness in a Danish interdepartmental 
administrative database compared with a population-based survey. Scand J Public Health 35:497-502

35. Jensen VM, Rasmussen AW (2011) Danish education registers. Scand J Public Health 39:91-94

36. Pedersen CB (2011) The Danish civil registration system. Scand J Public Health 39:22-25

37. Fendrich M, Weissman MM, Warner V (1990) Screening for depressive disorder in children and adolescents: validating the Center for Epidemiologic Studies Depression Scale for Children. Am J Epidemiol 131:538-551

38. OECD (2014) Mental health and work: Netherlands. OECD Publishing, Paris

39. OECD (2013) Mental health and work: Denmark. OECD Publishing, Paris

40. Lund T, Andersen JH, Winding TN, Biering K, Labriola M (2013) Negative life events in childhood as risk indicators of labour market participation in young adulthood: a prospective birth cohort study. PLoS ONE 8:e75860
41. VanderWeele TJ (2014) A unification of mediation and interaction: a four-way decomposition. Epidemiology 25:749-761

42. Seidler ZE, Dawes AJ, Rice SM, Oliffe JL, Dhillon HM (2016) The role of masculinity in men's help-seeking for depression: a systematic review. Clin Psychol Rev 49:106-118

43. Breslin G, McCay N (2013) Perceived control over physical and mental well-being: the effects of gender, age and social class. J Health Psychol 18:38-45

44. Rice SM, Aucote HM, Parker AG, Alvarez-Jimenez M, Filia KM, Amminger GP (2017) Men's perceived barriers to help seeking for depression: longitudinal findings relative to symptom onset and duration. J Health Psychol 22:529-536

45. Smith JP, Smith GC (2010) Long-term economic costs of psychological problems during childhood. Soc Sci Med 71:110-115

46. Bültmann U, Arends I, Veldman K, McLeod CB, Van Zon SKR, Amick BC (2020) Investigating young adults' mental health and early working life trajectories from a life course perspective: the role of transitions. J Epidemiol Community Health 74:179-181 